\title{
The role of skin coupling in the determination of vibrotactile spatial summation
}

\author{
JAMES C. CRAIG AND CARL E. SHERRICK ${ }^{2}$ \\ PRINCETON UNIVERSITY
}

\begin{abstract}
A series of three experiments was carried out to determine the effects of variation of static force and contactor area on both absolute thresholds and the magnitude of vibrotactile stimuli at frequencies of 20,80, and $250 \mathrm{~Hz}$. The findings were: (a) If contactor jenetration into the skin is constant, vibratory threshold amplitude falls off at the rate of $3 \mathrm{~dB}$ per doubling at $250 \mathrm{~Hz}$, in agreement with previous studies. (b) There is no increase in vibrotactile magnitude with increase in area at constant amplitude. (c) Increasing static force on the contactor produces an increase in the vibrotactile magnitude. Also, changing contactor force can shift the exponent of the vibrotactile magnitude function. Some discussion is given of the questions raised by the present research, in particular the question of whether static conditions modify not only the mechanics of wave propagation, but also the excitability of neural systems in the tissues.
\end{abstract}

One of the major problems in the field of sensory psychology has been the specification and control of the stimulus. In some modalities the problem has reached at least an adequate, if not an entirely satisfactory, solution. For example, when visual stimuli are employed, the amount of light entering the eye can be controlled by use of the artificial pupil, or the Maxwellian view, and the intensity and wavelength composition of light can be measured at the cornea. Similarly, for auditory stimuli, calibrated earphones and ear cushions may be employed and the in tensity of the stimulus in the ear canal can be measured as sound pressure. Vibratory stimuli applied to the skin are generally specified only by the frequency and amplitude of the of the vibration at the contactor and by the area of the contactor employed. There are a number of other factors that are either not specified, or vary from investigation to investigation, and these may have a profound effect on the results obtained.

Vetrillo (1962) has contributed substantially to the solution of the problem of standardization by introducing a fixed platform through which the vibrating contactor protrudes and touches the skin. The use of the static surround, which allegedly reduces the spread of surface waves on the skin (Verrillo, 1962), has undoubtedly contributed to the regularity of the functions that Verrillo reports. The presence of a surround is, however, only one of a number of static components of the stimulating conditions that may have an effect on such measures of vibratory sensitivity as absolute threshold and sensory magnitude. The present study was undertaken, in part, to investigate the effect on absolute threshold and the growth of sensory magnitude of three of these static factors, viz., force, penetration, and pressure

The problem of the control of such factors became evident when a reexamination was made of some earlier work on the growth of vibratory sensory magnitude as a function of number of vibrators. Craig (1966) had found that increasing the number of vibrators in a pattern produced an increase in the overall sensory magnitude of the pattern. The effect raises an important question: Is the increase in magnitude due to the increase in number of loci stimulated or is it due to the increase in the total area of skin being stimulated? In other words, if the area of a single contactor were increased, as opposed to increasing the number of vibrators, would the magnitude of the vibration increase in the same manner? The answer is not gained simply by noting the increase in sensory magnitude when the area is doubled or tripled, for when the area of a single contactor is increased, the mechanical coupling with the skin surface is altered. By coupling, it is meant those physical conditions that determine the maintenance of contact between the vibrator tip and the skin. Factors such as static force of the contactor, its area, the presence of a surround, and type of tissue, all determine the coupling. It can be demonstrated that if the contactor area is increased with static force held constant, both pressure and penetration will decrease. Verrillo (1962) chose 10 maintan constant the contactor penetration without suggesting a rational basis for his decision. The present investigation is part of an attempt to evaluate the effects on thresholds and sensory magnitude of modifying the area and force of the contactor.

A brief review of the interrelations among area, force, penetration, and pressure is in order at this point. If the area of a contactor is doubled while the force on it remains constant, the pressure is, by definition, halved, and, as will be shown, the penetration will decrease by an amount depending on the absolute values of the areas. To maintain constant pressure while area changes requires increases in force proporisonal 11 areal increases. Constant penetration over a range of areas generally requires a nonlinear increase in force.

\section{EXPERIMENT 1}

The first experiment was concerned with the effect of coupling factors on the spatial summation of vibratory stimul at threshold. Some investigators have cxammed the afuet if the force on vibratory thresholds and noted that increasing force reduces the amount of displacement amplitude required for threshold (Cohen \& Lindley, 1938). Other investigators have demonstrated that increasing the amount of penetration on the contactor in to the skin reduces the absolute threshold (Babkin, Rozen, Tumarkina, \& Chernyak, 1961; Verrillo, 1966) [Intil much more is known about the biophysical factors that affect vibratory sensitivity, it is not possible to single out the coupling parameter that must be controlled. However, it is possible, within the framework of a particular problem such as spatial summation, to examine what would happen if one or more of these factors were held constant.

In a series of papers beginning in 1962, Verrillo examined many of the parameters that affect the vibrotactile spatral summation at threshold. For frequencies of vibration between 80 and $250 \mathrm{~Hz}$, as the contactor area is doubled, there is a 3-dB decrease in the amount of displacement amplitude required for threshold. At lower frequencies, increases in contactor area do not produce any change in absolute threshold. In his experiments Verrillo has usually held constant the penetration of the contactor isto the skin as the area of the contactor was increased. Experiment l was concerned with the question of the effect of areal increase on spatial summation at threshold, when force, penetration, or pressure were held constant.

\section{Method}

Observers. Os were laboratory personnel and paid undergraduate volunteers. Os received several hours of practice before data collection was begun. 
Apparatus. For absolute threshold measurement, the signal from a Hewlett-Packard Model $200 \mathrm{CD}$ oscillator was gated by a Grason-Stadler Model 829D electronic switch, amplified by a General Radio Type 1206-B amplifier, and attenuated by a Hewlett-Packard Model $350 \mathrm{D}$ attenuator. The attenuator output was matched by a UTC Type CVL-1 transformer to the 10-ohm impedance of a Grason-Stadler Model E 3262A recording atteriuator. A resistive network matched the output of the recording attenuator to the 3-ohm coil of a Goodmans V-47 vibrator. The piston of the vibrator was fitted with a Lucite rod that was drilled to accept an Endevco Model 2222 accelerometer, and tapped internally at its upper end to receive any of three of the Teflon contactors that were to drive the skin. When one of the contactors was screwed into place, the accelerometer was clamped firmly within the rod, with its wire lead projecting from one side. An MB Model N504 amplifier conditioned and transferted the accelerometer signal to a General Radio Type 1564-A vibration analyzer. When the $80-\mathrm{Hz}$ signal was studied, two Krohn-Hite Model 310-C filters were interposed between the $\mathrm{MB}$ amplifier and the wave analyzer to block the $60-\mathrm{Hz}$ hum. At other frequencies, the one-tenth-octave band-pass filter circuit of the wave analyzer was enough to block noise.

The system was calibrated by visual means with the aid of a General Radio Type 1531-A Strobotac, and a microscope, by a method described by Geldard (1940). The accelerometer voltage, read at the wave analyzer, was recorded for several values of displacement of the vibrating contactor, and a calibration curve was plotted for each frequency to be studied. The plot of accelerometer voltage vs displacement was linear over the entire ratige examined, for all frequencies.

To ensure stability of threshold measurement within and between sessions, as well as to provide a sensitive system for controlling the static force of the contactor on the skin, there was constructed a stable support holding a Harvard trip balance and a rgid metal contactor surround. The balance rested on a level, massive surface, and was loaded with the vibrator on the weighing pan and a standard counterweight on the tare pan. A rigid support above the balance held one of a series of removable brass plates that served as the surround for one of the vibrator contactors. When the O's volar forearm rested on the plate, the balance could be adjusted by adding or subtracting small (ca. $10 \mathrm{mg}$ ) weights to the tare pan in order to raise or lower the contactor through the hole in the brass plate to touch the skin. With the aid of calibration marks on the contactor shaft and a dissecting microscope with a calibrated eyepiece, movements of the contactor of less than $0.1 \mathrm{~mm}$ could be observed, and the precise point of first contact of the skin with the contactor was visible.

The O's arm was supported on either side of the surround, i.e., at the elbow and the wrist, by inflatable rubber pods adapted from football bladders. The simple pneumatic arm rest proved to be effective in preventing stasis and discomfort in the $O$ even when he remained for $30 \mathrm{~min}$ in the same position. To reduce ballistic motions of the arm from pulse and muscle tremors, sandbags were laid over the portions of the arm supported by the Jods. A comfortable chair was provided for the $O$, who was fitted with headphones that generated a white noise to mask out all ambient sounds.

Procedure. An area of skin on the O's volar forearm approximately $10 \mathrm{~cm}$ from the elbow was marked and served for all threshold measurements. The smallest contactor, $3.25 \mathrm{sq} \mathrm{mm}$ $\mathrm{n}$ area, and the surround corresponding to it, $2 \mathrm{~mm}$ in diam arger, were the first installed for measurement. With the O's arm ositioned so that the marked area of skin was over the opening of the surround, weights were added to the tare pan of the salance until the contactor tip just touched the $O$ 's skin. Additional weights were added to the tare pan until the contactor penetrated his skin $1 \mathrm{~mm}$. The $\mathrm{O}$ was presented with a $1240-\mathrm{msec}$ burst of vibration every $2500 \mathrm{msec}$ at a frequency of either 20 , 80 , or $250 \mathrm{~Hz}$, depending upon the experimental condition selected. By means of a foot switch controlling the recording attenuator, the $\mathrm{O}$ tracked his threshold. The median attenuation for three ascending and three descending tracks was recorded, the recording attenuator was set at that level of attenuation, the vibrator was steadily energized, and the resulting voltage output of the accelerometer was read from the vibration analyzer. The voltage was converted to displacement in microns peak-to-peak by means of the previously generated calibration curves.

The stimulating system was disengaged from the O's skin and the contactor and surround were replaced by the next largest contactor and surround in the series. The vibrator was again raised until the contactor just touched the O's forearm, and he tracked his absolute threshold for the second area with three different couterbalancing forces. One force was the same as had been used in the previous threshold measurement (constant force condition). The second force produced a $1-\mathrm{mm}$ penetration into the skin (constant penetration condition). The third force produced the same pressure on the contactor as in the previous threshold measurement (constant pressure condition). Finally, thresholds were measured for the third and largest contactor area under the three conditions of constant force, penetration, and pressure.

At the time that thresholds were determined, measurements were made of the amount of penetration of the contactors into the skin as a function of the static force on the nonvibrating contactor. While $\mathrm{E}$ viewed the contactor through the binocular microscope, he raised the vibrator, by adding weights to the tare pan of the balance, until the cotıtactor just touched the S's forearm. For each additional weight added to the tare pan, the amount of displacement of the contactor into the skin was recorded. Similar measurements were made with all three contactor areas and surrounds.

\section{Results and Discussion}

The results of the penetration measurements are shown in Fig. 1. Each point represents the median of seven measurements. The slope of the power function relating displacement and force is 0.64 , and the intercept depends on the surface area of the contactor. Additional measurements made on the arm without surround and on the thenar eminence both with and without surround show that the slope of the function remains unchanged.

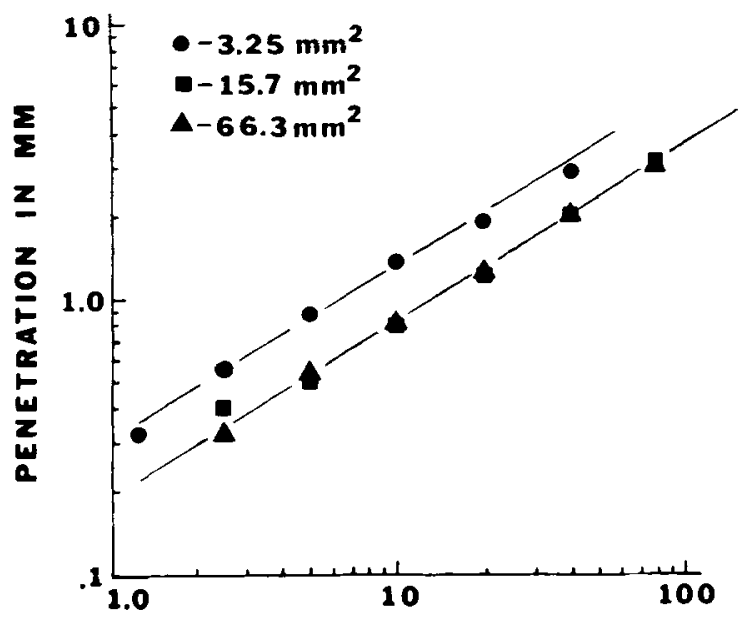

FORCE IN GRAMS

Fig. 1. Depth of penetration into the skin for contactors of different area as a function of the amount of static force. 


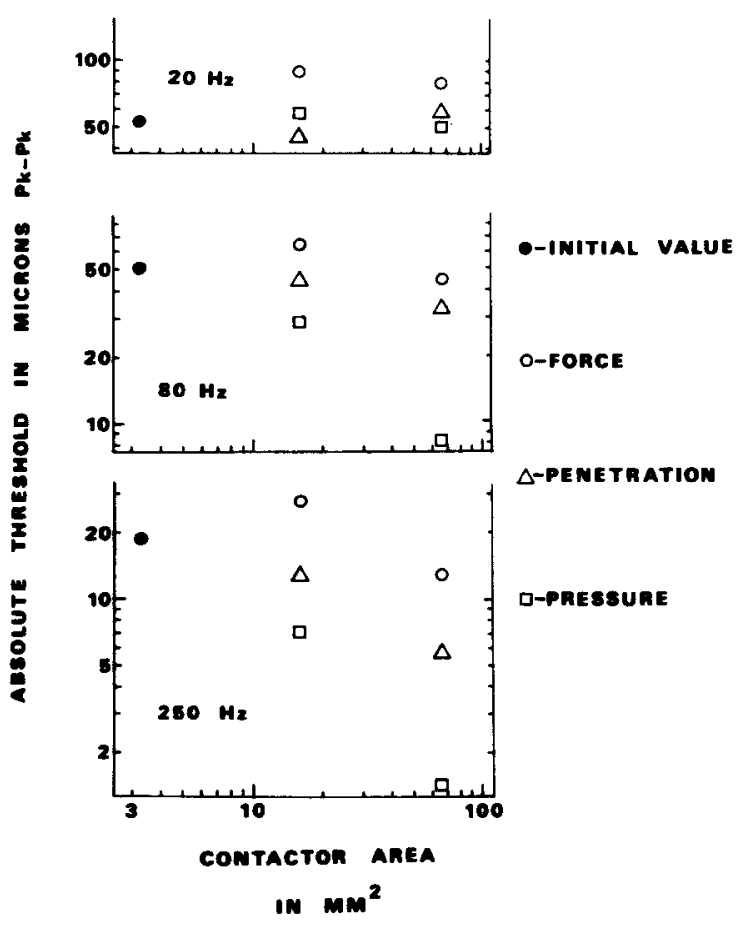

Fig. 2. Absolute threshold as a function of the surface area of the contactor at three frequencies. The filled circles (initial value) refer to measurements made with a contactor $3.25 \mathrm{sq} \mathrm{mm}$ in area and a force on the contactor that produces $1 \mathrm{~mm}$ of penetration into the skin. The other symbols refer to conditions in which either the force was the same as that used at the initial value or the penetration or pressure was the same.

Measurements by Franke (1951) suggest a similar function.

It is clear that for smaller contactor areas, the maintenance of constant penetration when the contactor area is increasing requires an increase in the amount of force. On the other hand, with penetration held constant, pressure must decrease as the area is increased.

The results of the threshold measurements are shown in Fig. 2. Each point represents the median of 10 measurements. The results with penetration held constant are in general agreement with those of Verrillo (1968). Holding either force or pressure constant produces altogether different results as area is increased, especially at the higher frequencies. Unless and until the precise effect of static factors on the mechanical properties of the skin is known, and there is understanding of the way in which the receptors in the skin are affected by changes in its properties, the choice of the factors to hold constant cannot be made with absolute certainty.

Verrillo (1966) has argued that the reduction of threshold of $3 \mathrm{~dB}$ per doubling of contactor area brings the skin into line with other modalities. Craig (1968) has shown that doubling the area of vibrotactile stimulation by adding a second locus produces a $2.5 \mathrm{~dB}$ decrease in threshold. In Verrillo's study, penetration was held constant and in Craig's, penetration and pressure were constant. If one argues that the simplest system is one in which perfect spatial integration of energy occurs, then penetration must be the significant correlate of skin coupling. With our present understanding of the biophysics of the skin, it may be best to accept as standard those conditions that yield the simplest functional relations. The adoption of the static surround and a condition of constant contactor penetration would therefore seem advisable.

\section{EXPERIMENT 2}

Craig (1966) demonstrated the regularity of increase of overall vibrotactile sensory magnitude when the number of vibrators was increased. If summation occurs at threshold with an increase in area at a single locus, will it occur as well at suprathreshold values, presumably to be perceived as an increase in sensory magnitude? Experiment 2 was designed to answer this question in connection with the influence of the coupling factors studied in Experiment 1 .

\section{Method}

Apparatus. The apparatus previously described for threshold determinations generated a stimulus that was presented to the O's right arm. A second vibration generating system constructed along the lines of the one already described controlled a stimulus presented to the $O$ 's left arm.

The signal from a General Radio Type 1310 oscillator was first gated through the second channel of the Model $829 \mathrm{D}$ Grason-Stadler switch, then amplified, attenuated, transformed, and sent to a second Goodmans V-47 vibrator. The second vibrator was fitted with a velocity-sensing pickup (Geldard \& Sherrick, 1966), and was calibrated for displacement amplitudes at $60 \mathrm{~Hz}$ only. The oscillator signal was synchronized with the $60-\mathrm{Hz}$ power line signal to prevent beating effects.

A second trip balance served to support the vibrator, and the tare pan was loaded to provide a constant $50 \mathrm{~g}$ force on the contactor against the skin. The contactor tip, $66.4 \mathrm{sq} \mathrm{mm}$ in area, was centered in a hollow Teflon cylinder that acted as a static surround and as a form for the coil of the velocity sensing pickup system. When $O$ was properly seated, the left arm was loaded with sandbags to reduce motion of the skin at the contactor site. When the vibration intensity at the left arm was being adjusted by the 0 , the recording attenuator was switched to the second channel so he could raise and lower the intensity level by means of a foot switch that controlled the attenuator.

Procedure. An area of skin on O's right wolur fureame was marked and positioned over the smallest surroumd The vihrator, with the smallest contactor attached, was raised untii it just touched O's skin. After sufficient weight to produce a $1-\mathrm{mm}$ displacement into the skin had been added to the tare pan of the balance, $\mathrm{O}$ tracked his threshold with the recording allentuatur for a $1240-\mathrm{msec}$ burst of $250-\mathrm{Hz}$ vibration. The amplitude of the vibration was raised to $10 \mathrm{~dB}$ above threshold and was held constant, as the standard, throughout the experimental session. At $O$ 's left volar forearm, on the approximately homologous site, the second vibrator was placed. O controlled the amplitude of the $60-\mathrm{Hz}$ vibration at the left arm with the recording attenuator, and was required to manipulate the intensity to match the magnitude at the left arm to that of the right arm. The $60-\mathrm{Hz}$ signal was $1240 \mathrm{msec}$ in duration and was presented simultaneously with the signal on the right arm. The median attenuation for three ascending and three descending tracks was recorded. With the recording attenuator set at that level of attenuation, the vibrator was energized and the resulting voltage output of the velocity sensing pickup was converted to displacement in microns peak to peak. One magnitude match was made with the smallest contactor area and surround. The contactor and surround were then changed and $\mathbf{O}$ made magnitude matches under conditions of constant force, penetration, and pressure on the right arm for the two largest contactors.

In order to evaluate summation effects at 20 and 80 $\mathrm{Hz}$, it was necessary to decide whether the initial value of amplitude at the right arm for these frequencies should be (a) equal in amplitude to the initial value 


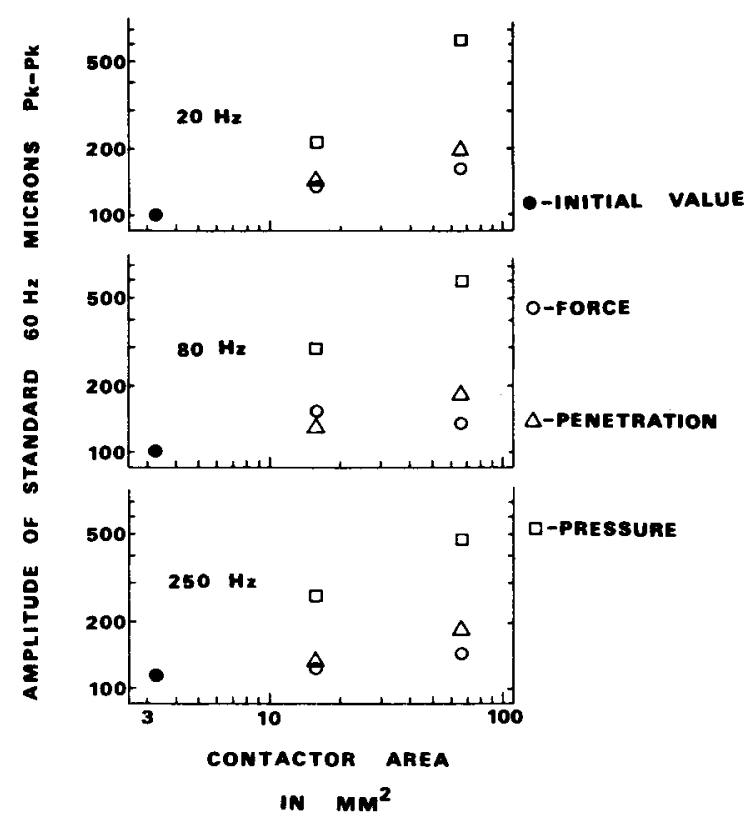

Fig. 3. Amplitude of $60-\mathrm{Hz}$ vibration set by $\mathrm{Os}$ to be equal in sensory magnitude to vibrations of constant amplitude as a function of the surface area of the contactor. Symbols as in Fig. 2.

for $250 \mathrm{~Hz}$, (b) at a value of $10 \mathrm{~dB}$ SL for each frequency, or (c) at a value that would yield a sensory magnitude equal to that of the initial value for $250 \mathrm{~Hz}$. The last alternative was chosen, since it appeared that shifts from a common magnitude were the significant effects to be observed.

The procedure for obtaining constant magnitudes for initial values at all frequencies was straightforward: The smallest contactor area was attached to the vibrator at the right arm, and its force was adjusted for a $1-\mathrm{mm}$ penetration. The $60-\mathrm{Hz}$ signal at the left arm was set at the average value $O$ had given when he equated the $60-\mathrm{Hz}$ signal to the initial value of the $250-\mathrm{Hz}$ signal previously. The 20 - or $80-\mathrm{Hz}$ signal on the right arm was then adjusted for equality to the left arm. The resulting initial value of amplitude was maintained constant for the two larger areas, and the amplitude of the $60-\mathrm{Hz}$ signal was manipulated by $\mathrm{O}$ to match the magnitude at the right arm, as before.

Results and Discussion

The medians of 10 measurements at each point are shown in Fig. 3. As evidenced by the fact that Os made only small increases in the $60-\mathrm{Hz}$ comparison stimulus, there is apparently little increase in sensory magnitude as the area of a single contactor is increased when either force or penetration is held constant. This appears to be the case for all three frequencies tested. However, when pressure is held constant, there is a regular increase in sensory magnitude as the area increases, at the rate of approximately $3 \mathrm{~dB}$ per doubling of area.

For the largest area the median value for the constant-force condition was $6 \mathrm{~g}$, for the constant-penetration condition $11 \mathrm{~g}$, and for the constant-pressure condition $120 \mathrm{~g}$. In Fig. 3, for the largest area, $66.3 \mathrm{~mm}^{2}$, the constant pressure produced the greatest increase in sensory magnitude, with constant penetration next, and constant force producing the least increase. It would appear that there is an increase in the sensory magnitude of vibration, if amplitude of vibration and contactor area are held constant, as the static force is increased, an observation that has been made before (Herzog, 1906; von Frey, 1915). To hold pressure constant as area is increased requires an increase in static force. The median force on the smallest area was $6 \mathrm{~g}$. To produce the same pressure on the next largest area $30 \mathrm{~g}$ were required, and on the largest area $120 \mathrm{~g}$ were required. The observation that increasing force increases the sensory magnitude of vibration in conjunction with the fact that increasing forces were required to maintain pressure constant as area was increased makes the interpretation of the results of Experiment 2 ambiguous.

\section{EXPERIMENT 3}

To resolve the ambiguity of Experiment 2, i.e., whether increasing area at constant pressure causes the rise in sensory magnitude, or whether increasing force is alone sufficient, Experiment 3 was undertaken.

\section{Method}

Apparatus and procedure. The $\mathrm{O}$ confronted the same apparatus as in Experiment 2. Only one circular contactor, $15.7 \mathrm{~mm}^{2}$ in area, was used. The vibrator was raised until the contactor just touched the surface of O's right volar forearm. Additional weights ranging from 2.5 to $80 \mathrm{~g}$ were added to the tare pan of the balance. The vibrator was energized with a burst of either $20-80-$, or $250-\mathrm{Hz}$ vibration at the same duty cycle previously presented. The amplitude of the vibration was the median of the amplitudes $\mathbf{O}$ had obtained for the same conditions in Experiment 2. The amplitude remained constant for $O$ throughout an experimental session. $O$ again matched the magnitude of the $60-\mathrm{Hz}$ vibration on his left arm to that on the right arm. Weights were then added to or removed from the tare pan of the balance in irregular order, and $O$ repeated the task.

\section{Results and Discussion}

The medians of eight observations for each point are shown in Fig. 4. It is apparent that increasing the static force on the contactor results in an increase in the sensory magnitude. Moreover, the increase is, in general, enough to account for the results of the constant pressure condition of Experiment 2. For example, at $250 \mathrm{~Hz}$ in Experiment 2, increasing the area from $3.25 \mathrm{~mm}^{2}$ to $15.7 \mathrm{~mm}^{2}$ with pressure held constant required an increase in the $60-\mathrm{Hz}$ vibration from 112 to 245 microns or $6.8 \mathrm{~dB}$. In order to maintain constant pressure, the static force on the contactor was increased from $6 \mathrm{~g}$ to $30 \mathrm{~g}$. From Fig. 4 it can be seen that increasing the static force from $6 \mathrm{~g}$ to $30 \mathrm{~g}$ would result in an increase in the amplitude of the matching vibrator of 130 to 340 microns or $8.3 \mathrm{~dB}$. The other frequencies, 20 and $80 \mathrm{~Hz}$, exhibit a similar effect. From these results we conclude that the apparent increase in sensory magnitude with increasing area under the constant pressure condition was the result of increasing static force and that, in fact, there is little increase in sensory magnitude obtained by simply increasing contactor area.

An interesting aspect of the data presented in Fig. 4 is that the resulting functions show two limbs: a lower branch in which increasing force has little or no effect on magnitude, and an upper branch in which the magnitude increases proportionately with increasing force. It would appear that the break between the two limbs occurs at a lighter force with higher frequencies. Some additional observations on the point at which the break occurs in the magnitude growth functions provides further evidence that static pressure is not the important variable in controlling vibratory loudness. Using approximately the same median amplitude as before, further measurements were made of the growth of magnitude with static force at $80 \mathrm{~Hz}$ for two areas. The medians of eight observations per point are shown in Fig. 5. These results also show a two-limbed function with a break for both areas at about $13 \mathrm{gm}$. For a contactor $15.7 \mathrm{~mm}^{2}$ in area, this force produces a static pressure of $0.83 \mathrm{gm} / \mathrm{mm}^{2}$, while for a contactor $66.3 \mathrm{~mm}^{2}$ the same force produces a static pressure of only $0.20 \mathrm{gm} / \mathrm{mm}^{2}$. If pressure were the important parameter to be controlled in magnitude measurements, one would expect that for two different contactor areas the break in the function would 


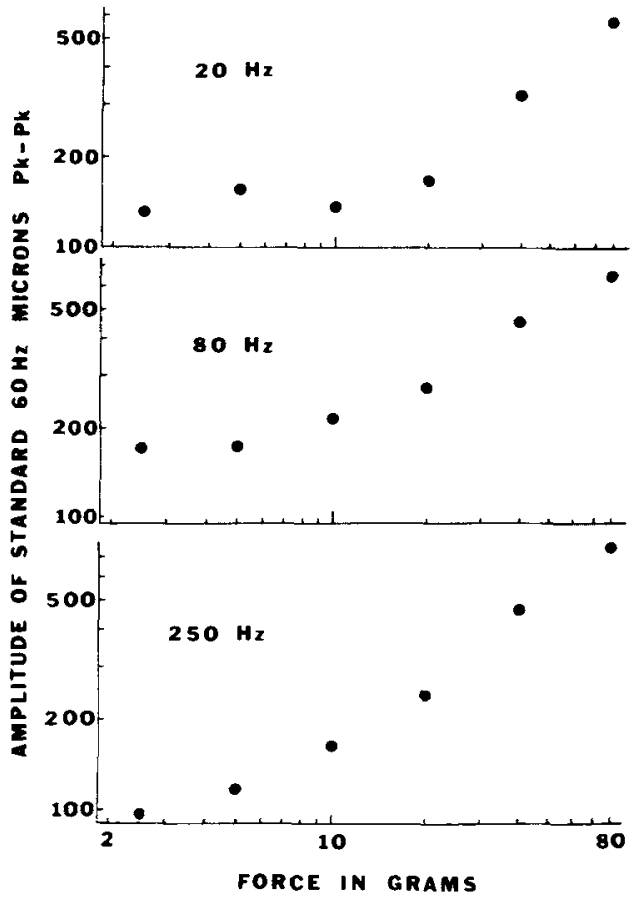

Fig. 4. Amplitude of $60-\mathrm{Hz}$ vibration set by $\mathrm{Os}$ to be equal in sensory magnitude to vibrations of constant amplitude as a function of the amount of static force on the contactor. Contactor was $15.7 \mathrm{sq} \mathrm{mm}$ in area.

occur at the same pressure rather than at the same force, whereas the reverse is true. It should be noted that with the two contactors used, the same force produces approximately the same penetration (Fig. 1). Without measurements with several more contactor areas, it is not possible to speculate whether force or penetration or perhaps some other static component is the important variable which affects vibrotactile magnitudes.

The data presented in Figs. 2 and 3 reflect on another area of interest in vibrotactile research, viz., magnitude growth functions. At $20 \mathrm{~Hz}$ for a given area the absolute threshold changes little with increases in force, whereas sensory magnitude may increase significantly. For example, the absolute threshold with the largest contactor area at approximately $11 \mathrm{~g}$ was 60 microns; at $120 \mathrm{~g}$ it was 55 microns. When the amplitude was raised to 315 microns, an increase of about $15 \mathrm{~dB}$, the amplitude of the $60-\mathrm{Hz}$ vibration needed for a magnitude match to the $20-\mathrm{Hz}$ vibration with $11 \mathrm{~g}$

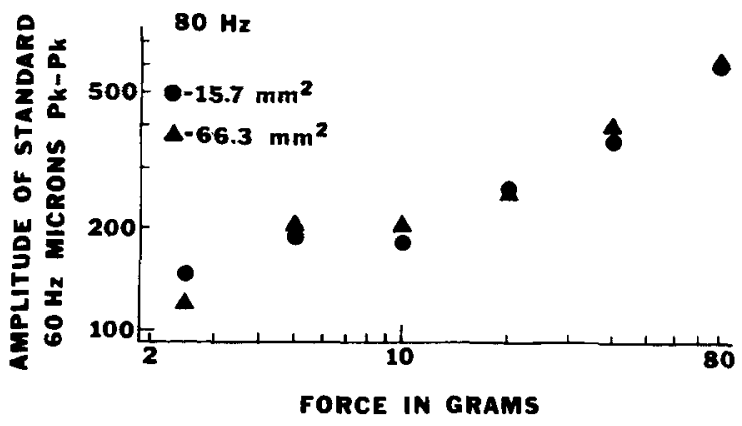

Fig. 5. Amplitude of $60-\mathrm{Hz}$ vibration set by $\mathrm{Os}$ to be equal in sensory magnitude to vibrations of constant amplitude delivered through two contactors of different area as a function of the amount of static force. of static force was 200 microns, whereas with $120 \mathrm{~g}$ of static force the amplitude for a magnitude match was over 600 microns. In other words, magnitude growth functions, as measured in $\mathrm{dB}$ of amplitude above threshold, will exhibit slopes that change as a function of the static force applied to the contactor. This conclusion appears to hold for 80 and $250 \mathrm{~Hz}$, although the differences in growth functions for different forces do not appear to be as great.

\section{GENERAL DISCUSSION}

The present report leaves unexplored many questions of importance to the problem of summation of excitations in sensory systems. Nothing has been said, for example, of the role of inhibition in the manipulation of coupling factors. Does the isolation of the excited area by a static surround expose the areal summation first noted by Verrillo because peripheral excitation is reduced, or because peripheral inhibitory effects are reduced? If the model of energy summation with areal increase at threshold is the desirable one, then penetration is the correlate of coupling to be held constant, as we have shown. Why, then, does not a similar effect hold for summation at suprathreshold values? Further, doubling contactor force increases magnitude by approximately $3 \mathrm{~dB}$. Does this mean that force is responsible for energy summation in the tissues at supraliminal values? Is it possible that the adaptation of receptors to static forces modifies their excitability to vibratory stimuli? Finally over what range of vibrotactile magnitude does contactor force affect the growth functions? The hypothesis of adaptation of receptors to static forces suggests that vibrotactile growth functions may exhibit an upper threshold for high values of force and vibration amplitude, similar to that suggested by Harper and Stevens (1964) for the judgment of hardness magnitudes.

\section{REFERENCES}

BABKIN, V. P., \& ROZEN, O. M., \& TLIMARKINA, L. N. \& CHERNYAK, R. 1. Investigations of vibration sensilivits ana idu fors affecting it. Biophysics, 1961, 6, 39-43.

COHEN, L. H., \& LINDLEY, S. B. Studies in vibratery sensibility. American Journal of Psychology, 1938, 51, 44-63.

CRAIG, J. C. Vibrotactile loudness addition. Percepuon \& Pry hopingsics. $1968,4,351-354$.

CRAIG, J. C. Vibrotactile spatial summation. Perception \& Psychophysics, 1968, in press.

FRANKE, E. K. Mechanical impedance measurements of the human body surface. Air Force Technical Report No.6469, 1951, Wright-Patterson Air Force Base, Dayton, Ohio.

GELDARD, F. A. The perception of mechanical vibration: II. The response of pressure receptors. Journal of General Psychology, 1940, 22, 271-281.

GELDARD, F. A., \& SHERRICK, C. E. Princeton Cutaneous Research Project Report No. 8, September, 1966.

HARPER, R., \& STEVENS, S. S. Subjective hardness of compliant materials. Quarterly Journal of Experimental Psychology, 1964, 16, 204-215.

HERZOG, F. Uber das Vibrationsgefuhl. Deutsche Zeitschrift für Nervenheilkunde, $1906,31,96-107$.

VERRILLO, R. T. Investigation of some parameters of the cutancous threshold for vibration. Journal of the Acoustical Society of America, $1962,34,1768-1773$.

VERRILLO, R. T. Effect of spatial parameters on the vibrotactile threshold. Joumal of Experimental Psychology, 1966, 71, 570-575.

VERRILLO, R. T. A duplex mechanism of mechanoreception. In D. R. Kenshalo (Ed.), The skin senses. Springfield, Ill.: Thomas, 1968. Pp. 139-156.

Von FREY, M. Physiologisches Versuch über das Vibrationsgefühl. Zeitschrift für Biologie, 1915, 65, 417-427.

\section{NOTES}

1. This study was supported by Grant NB-04755 from the National Institutes of Health, U. S. Department of Health, Education, and Welfare.

2. Address: Department of Psychology, Princeton University, Princeton, New Jersey 08540 .

(Accepted for publication January 27, 1969.) 